\title{
Editorial 24/2: Electronic Markets and journal sections
}

\author{
Rainer Alt • Hubert Österle
}

Published online: 15 May 2014

(C) Institute of Information Management, University of St. Gallen 2014

Dear readers of Electronic Markets,

The world of academic publishing has profoundly changed in the last decade. A first transformational element is rooted in the ever-increasing importance of journal publications in academic qualification and assessment processes. Junior researchers already strive for journal publications in their dissertation work and tenure without a solid publication record is hardly conceivable. With journal articles becoming a key currency within academia, many journals have emerged and the vast number of possible outlets also features important differences regarding the quality of the published research. Institutions, such as the index systems (e.g. the "Social Science Citation Index", SSCI by Thomson Reuters) or shortlists (e.g. the "Basket of Eight" by the Association for Information Systems, AIS), aim to provide orientation regarding quality measures, such as double-blind review processes and the availability of English articles and abstracts. For example, the total number of journals covered in the SSCI grew from 1, 697 in 1998 to 2, 697 in 2009 (Larsen and von Ins 2010, p. 591) and to 3, 131 in 2014 (Thomson 2014). The number of journals is expected to rise even further in the future, especially if conference proceedings, open archives and document servers are additionally taken into account (Larsen and von Ins 2010, p. 600). However, many authors are inclined to submit their work to journals with a high reputation in these rankings. Journals with high impact factors (IF) typically also receive more submissions than journals

\author{
R. Alt $(\bowtie)$ \\ University of Leipzig, Grimmaische Str. 12, 04109 Leipzig, \\ Germany \\ e-mail: rainer.alt@uni-leipzig.de \\ H. Österle \\ University of St. Gallen, Müller-Friedberg-Str 8, 9000 St. Gallen, \\ Switzerland \\ e-mail: hubert.oesterle@unisg.ch
}

with a lower IF or without an IF. Consequently, journals will aim at attaining higher scores in these rankings and journals need to position themselves in this increasingly competitive marketplace.

A second transformational element is the digitization of the entire media value chain. In particular, the role of physical copies accessed either in a library or ordered on a subscription basis has diminished. This has changed the consumption pattern: first, most articles are nowadays accessed from electronic sources and are often printed for final reading; second, the amount of papers faculty members use in average has increased and a higher number of older publications from a broader spectrum of journal titles are cited; third, the average time for reading a single paper has decreased (Tenopir et al. 2009). Publishing companies have responded by offering electronic content, aggregators such as Ebsco, Emerald or ProQuest have entered the market and open access journals have emerged. It is the nature of these databases that articles are usually retrieved by keywords or other search criteria, but the traditional issue which has until now been available in (physical) libraries is about to disappear. Following the first transformational element authors are motivated to have their research accepted in a specific journal, but the publication in the physical issue is not key as long as the article is available online. In the first place, the transformation presents a challenge for publishing companies which need to adapt their business model. It also means that the content of a specific article - being a function of factors, such as review processes, quality of submitted material and a journal's IF - is even more critical. Content-wise, the responsibility is not with the publishing company, but with editors from academic institutions and a board of peers.

From the Electronic Markets' perspective, it has been emphasized that the technical soundness of a submitted article is only a prerequisite. More important is that the content reveals some novel finding that impacts developing, using or 
understanding the use of information technology (IT) within economic value chains. Recently, Electronic Markets has reorganized the journal sections and now publishes peerreviewed content in four sections (see Fig. 1 and www. electronicmarkets.org/ for more information):

- The first section comprises traditional research articles which are either submitted for a special issue or as manuscripts for general research. In line with its scope, Electronic Markets seeks high quality research papers which may follow diverse methodological directions. Conceptual and theory-development papers, empirical hypothesis testing, and case-based studies are all welcome. To ensure that only promising submissions are forwarded to our reviewers, submissions are initially screened regarding the fit to the scope of Electronic Markets, methodological soundness and the potential contribution of the paper to theory and practice.

- The second section emphasizes case study papers as a specific form of research papers. It follows the observation that retrospective research has become a widespread research tradition and provides a platform for case- and design-oriented prospective research which is critical for identifying and analyzing innovative and relevant research topics (Alt and Osterle 2014). Case study papers aim to obtain in-depth insights into how IT is used in a business setting and to understand the intricate network of factors that determine the success of IT-based solutions, such as industry dynamics, the fit with organizational design or social embeddedness.

- The third section includes position papers which do not focus on presenting the results of finished research, but on introducing thought-provoking opinions and aspects in the area of electronic markets and networked business. Besides offering novel and fresh perspectives, position papers should be well-argued and articulated to address emergent, controversial, even paradoxical issues. To merit publication in a scientific journal, position papers also need to follow scholarly reasoning and feature a rigorous and evidence-based line of argumentation.

- The fourth section finally contains content that is not subject to double-blind reviewing by peers from the editorial board or by (Senior or Associate) editors, but rather limited to the check (scope, methodology, formal issues etc.) on behalf of the Editors-in-Chief which is standard for all content appearing in Electronic Markets. Among the examples are editorials, prefaces to the special issue sections (e.g. Wohlgemuth et al. 2014), book reviews (e.g. Riedl 2011) and the like.

Electronic Markets has a long tradition in publishing special issues to attract content in relevant areas, such as recently on mobile health (Vogel et al. 2013), the Future Internet (Colomo-Palacios et al. 2013) or Internet Marketing (Holland et al. 2013). In addition to focusing on a specific topic, another direction for special issues is more eventoriented and compiles best papers from conferences (see Alt and Osterle 2013), such as the Bled conference (Zimmermann and Lechner 2013). The present issue illustrates that special themes also address current issues. In this case, we are glad that a team of four guest editors (Sven Wohlgemuth, Stefan Sackmann, Noboru Sonehara, and A Min Tjoa) has organized a call for papers for "Security and Privacy in Business Networking". This was in early 2012 and well before the widespread monitoring and intelligence on behalf of governments and others shed light on the relevance of security and privacy aspects. In their comprehensive preface our guest editors provide an introduction into the topic which not only describes the role of security in networked businesses, but also paints a picture of the required components for future applications which follow the concept of resilience (Wohlgemuth et al. 2014). The overview also serves to position the four papers included in this special section.

In addition to the four special issue papers, the present issue includes two general research papers. The first is also linked to the special theme and investigates the question "Is the influence of privacy and security on online trust the same for all type of consumers?". Using an empirical research model Isabel P. Riquelme and Sergio Román conclude that the perception of privacy and security influences how consumers trust a certain online retailer. They show that understanding individual factors, in particular personal openness and computer literacy, and demographic factors, such as age and gender, yields interesting insights for theory and practice. The second general research paper aims at "Detecting incorrect product names in online sources for product master data". The authors Stephan Karpischek, Florian Michahelles and Elgar Fleisch suggest a solution that contributes to the quality of product data that, for example, is provided in a standardized form (GTIN) on retailer websites. Using data from barcode scans the authors find out that on average $2 \%$ of all product information is incorrect and show that machine-learning approaches may be helpful in increasing the problem of data quality.
Fig. 1 Sections of Electronic Markets

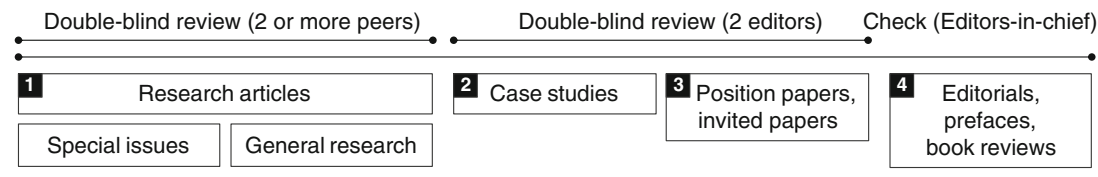


We would like to thank the authors, guest editors and all reviewers involved in completing this issue for their effort. In case you have any input or feedback on the sections of Electronic Markets and possible future sections we would be happy to hear from you.

Best regards from Leipzig and St. Gallen,

Rainer Alt, Hubert Österle

\section{References}

Alt, R., \& Österle, H. (2013). Electronic Markets and conference contributions. Electronic Markets, 23(4), 267-268.

Alt, R., \& Österle, H. (2014). Electronic Markets and practice-orientation. Electronic Markets, 24(1), 1-4.

Colomo-Palacios, R., Soto-Acosta, P., Ramayah, T., \& Russ, M. (2013). Special issue on electronic markets and the future internet: from clouds to semantics. Electronic Markets, 23(2), 89-91.
Holland, C. P., Diehl, K., \& Herrmann, A. (2013). Introduction to the special theme on Internet marketing. Electronic Markets, 23(3), $175-176$.

Larsen, P. O., \& von Ins, M. (2010). The rate of growth in scientific publication and the decline in coverage provided by science citation index. Scientometrics, 84(3), 575-603.

Riedl, C. (2011). Book review of "Business network transformation" by Jeffrey Word (ed.). Electronic Markets, 21(3), 209-211.

Tenopir, C., King, D. W., Edwards, S., \& Wu, L. (2009). Electronic journals and changes in scholarly article seeking and reading patterns, in: ASLIB proceedings: new information. Perspectives, 61(1), $5-32$.

Thomson Reuters, (2014). Social Sciences Citation Index - Journal List, http://ip-science.thomsonreuters.com/cgi-bin/jrnlst/jlresults.cgi? $\mathrm{PC}=\mathrm{SS}$, accessed 01.05.14.

Vogel, D., Viehland, D., Wickramasinghe, N., \& Mula, J. M. (2013). Mobile health. Electronic Markets, 23(1), 3-4.

Wohlgemuth, S., Sackmann, S., Sonehara, N., \& Tjoa A M, (2014). Security and privacy in Business Networking, in: Electronic Markets, 24(2).

Zimmermann, H.-D., \& Lechner, U. (2013). Preface to the special issue "Bled eConference 2011 and 2012". Electronic Markets, 23(4), 269-270. 